\title{
Consumption of meat in relation to physical functioning in the Seniors-ENRICA cohort
}

\author{
Ellen A. Struijk ${ }^{1,2^{*}}$, José R. Banegas ${ }^{1,2}$, Fernando Rodríguez-Artalejo ${ }^{1,2,3}$ and Esther Lopez-Garcia ${ }^{1,2,3}$
}

\begin{abstract}
Background: Meat is an important source of high-quality protein and vitamin B but also has a relatively high content of saturated and trans fatty acids. Although protein and vitamin B intake seems to protect people from functional limitations, little is known about the effect of habitual meat consumption on physical function. The objective of this study was to examine the prospective association between the intake of meat (processed meat, red meat, and poultry) and physical function impairment in older adults.
\end{abstract}

Methods: Data were collected for 2982 participants in the Seniors-ENRICA cohort, who were aged $\geq 60$ years and free of physical function impairment. In 2008-2010, their habitual diet was assessed through a validated computerassisted face-to-face diet history. Study participants were followed up through 2015 to assess self-reported incident impairment in agility, mobility, and performance-based lower-extremity function.

Results: Over a median follow-up of 5.2 years, we identified 625 participants with impaired agility, 455 with impaired mobility, and 446 with impaired lower-extremity function. After adjustment for potential confounders, processed meat intake was associated with a higher risk of impaired agility (hazard ratio [HR] for highest vs. lowest tertile: 1.33; $95 \%$ confidence interval [Cl]: 1.08-1.64; $p$ trend $=0.01$ ) and of impaired lower-extremity function (HR for highest vs. lowest tertile: $1.31 ; 95 \% \mathrm{Cl}: 1.02-1.68 ; p$ trend $=0.04$ ). No significant associations were found for red meat and poultry. Replacing one serving per day of processed meat with one serving per day of red meat, poultry, or with other important protein sources (fish, legumes, dairy, and nuts) was associated with lower risk of impaired agility and lower-extremity function.

Conclusions: A higher consumption of processed meat was associated with a higher risk of impairment in agility and lower-extremity function. Replacing processed meat by other protein sources may slow the decline in physical functioning in older adults.

Keywords: Physical functioning, Meat intake, Red meat, Processed meat, Poultry, Elderly, Agility, Mobility, SPPB

\section{Background}

Due to the increase in life expectancy over recent decades, older adults are becoming the largest segment of the population [1]. Consequently, more people are suffering from limitations in physical and cognitive functioning as well as disability, which have a major impact on the quality of life and use of health services [2]. To

\footnotetext{
* Correspondence: ellen.struijk@uam.es

1 Department of Preventive Medicine and Public Health, School of Medicine,

Universidad Autónoma de Madrid, Avda. Arzobispo Morcillo, 4, 28029 Madrid, Spain

${ }^{2}$ CIBERESP (CIBER of Epidemiology and Public Health), Madrid, Spain Full list of author information is available at the end of the article
}

ensure that people not only live longer but also have healthier lives, more knowledge is needed about the determinants of physical functioning. Some of the factors that have previously been associated with functioning impairment include chronic diseases, inflammation, oxidative stress, waist circumference, and modifiable health behaviors, including several dietary components [3-7].

Meat is an important source of high-quality protein because it contains large quantities of essential amino acids [8]. Therefore, higher animal protein intake has been associated with better physical functioning and with other age-related conditions, such as muscle strength and frailty 
among older populations [9-14]. In addition to protein, meat contains other nutrients, such as B vitamins, which may also be beneficial to physical functioning [15]. On the other hand, meat has a relatively high content of saturated and trans fatty acids [8]. The latest statement from the American Heart Association on dietary fats and cardiovascular disease concluded that lowering the intake of saturated and trans fats and replacing them with unsaturated fats reduces the incidence of cardiovascular disease [16]. In addition, a recent meta-analysis showed that red meat and processed meat consumption was associated with increased total, cardiovascular, and cancer mortality [17], with less conclusive results for unprocessed meat among studies conducted outside of the U.S. Therefore, understanding the health effect of habitual meat consumption in older adults is of great interest given the high prevalence of both cardiometabolic risk factors and malnutrition in this population, which produces loss of muscle mass and subsequent frailty and disability [18-21]. To our knowledge, only the Framingham Offspring study has assessed the association between red and white meat consumption and physical function; participants with a higher intake of red meat or poultry and fish had a lower risk of developing two or more functional impairments during the follow-up, although the association was only significant in those with high levels of physical activity [22].

The aim of this study was to investigate prospectively meat consumption (processed meat, red meat, and poultry) in association with self-reported (agility and mobility) and performance-based (lower-extremity function) domains of physical functioning in a European cohort of communitydwelling older adults.

\section{Methods}

\section{Study design and participants}

Data were taken from the Seniors-ENRICA cohort, whose methods have been reported elsewhere [23, 24]. In brief, the cohort was derived from the ENRICA study, which ran from 2008 to 2010 among individuals representative of the non-institutionalized adult population of Spain. The study participants, who were aged 60 years or older, comprised the Seniors-ENRICA cohort $(n=3289)$. At baseline, information on socio-demographic variables, lifestyle, health status, and morbidity was collected through a phone interview. Also, details of their food consumption were obtained, and a physical examination was performed by trained staff in their homes. Two waves of data collection were performed to update the information about the cohort, the first in 2012 and the second in 2015. In total, 1291 participants were lost during the follow-up (675 in the first wave and 616 in the second) and 177 deaths were identified (95 in the first wave and 82 in the second). The participants lost to follow-up were mostly women, had a lower educational level, and were more often obese. Their intake of the different categories of meat was similar in both groups.

Before our analysis, we excluded participants for whom we had no information on diet at baseline or during the follow-up or with an implausibly high or low energy intake (outside the range of 800-5000 kcal/day for men and 500-4000 kcal/day for women), leaving 2982 participants. Furthermore, we excluded those with impaired physical functioning at baseline or those for whom we had no information on physical function at baseline or during follow-up, depending on the domain investigated (the definitions of the three physical function domains are described below). Therefore, the number of participants available for the analysis varied for each domain of physical functioning investigated: 2681 for agility, 2732 for mobility, and 2982 for lowerextremity function, as measured using the Short Physical Performance Battery (SPPB). Since we did not perform the SPPB at baseline, we excluded participants who were frail at baseline as a proxy of impaired lower-extremity function. Frailty at baseline was defined with the Frail scale [25]. Parts of the methods have been described previously [15]. Study participants gave written informed consent. The study was approved by the Clinical Research Ethics Committee of La Paz University Hospital in Madrid.

\section{Study variables \\ Diet}

Information on food consumption was obtained through a validated computer-assisted face-to-face diet history, which was developed from the one used in the EPIC cohort study in Spain [26]. This instrument records the habitual consumption of 880 foods in the preceding year, and includes a set of photographs to help in the quantification of food portions. Energy intake and the intake of other nutrients were estimated using standard food composition tables for Spain [26]. Food consumption was assessed at baseline and again in 2012, and the cumulative average was used for this study. The validity of the diet history was assessed against seven 24-hour recalls over 1 year of 132 men and women, and showed good correlation coefficients for meat intake $(r=0.66)$ [26]. We grouped the different types of meat recorded into three mutually exclusive categories: processed meat (including bacon, salami, and sausages), red meat (including beef, lamb, and pork), and poultry (including several types of fowl and rabbit). Of note, in Spain, poultry accounts for most white meat consumption. Organ meat has not been taken into account due to its low intake.

\section{Physical function}

We assessed three different domains of physical functioning: agility, mobility, and lower-extremity function. Participants were deemed to have impaired agility when they answered "a lot" to the following question from the 
Rosow and Breslau scale [27]: "On an average day with your current health, would you be limited in bending and kneeling?" The categories of response were "yes, a lot," "yes, a little," and "not at all." In the same way, impairment in mobility was defined as answering "a lot" to any of the following questions from the Rosow and Breslau scale: "On an average day with your current health, would you be limited in the following activities: (1) picking up or carrying a shopping bag?; (2) climbing one flight of stairs?; (3) walking several city blocks (a few hundred meters)?" Limitation in the lower-extremity function was assessed with the SPPB, which includes three measurements: gait speed across $2.44 \mathrm{~m}$, the ability to rise from a chair five times consecutively, and standing balance using three hierarchical tandem tests [28]. Each component was scored on a four-point scale, and the total score was the sum of the three components (range 0-12). A higher score indicates better physical performance. Although the standard score for functional limitation is $\leq 9$, we used a $\leq 6$-point cut-off to improve the sensitivity.

\section{Other variables}

At baseline and at the follow-ups in 2012 and 2015, we obtained information on socio-demographic variables, lifestyle, anthropometrics, and disease history. Educational level was classified into primary, secondary, or university level, and smoking status as never smoked, former smoker, or current smoker. Weight and height were measured under standardized conditions. Body mass index (BMI) was calculated as weight $(\mathrm{kg})$ divided by height squared $\left(\mathrm{m}^{2}\right)$, and classified as $<25,25-29.9$, or $\geq 30 \mathrm{~kg} / \mathrm{m}^{2}$. Physical activity during leisure time (metabolic equivalent hours/week) was ascertained with the EPIC cohort questionnaire, validated in Spain [29]. Sedentary behavior was approximated by the time (hours/week) spent watching television. Cognitive function was assessed with the Mini-Mental State Examination (MMSE), and cognitive impairment was defined as a MMSE score <23 [30]. Participants also reported the following physician-diagnosed diseases: osteomuscular disease, cardiovascular disease, cancer, chronic lung disease, and depression requiring treatment.

All-cause deaths were ascertained by a computerized search of the National Death Index, which contains information on the vital status of all residents in Spain [31]. This information was available for $99.9 \%$ of the cohort.

\section{Statistical analysis}

A Cox proportional hazard analysis was performed to determine the hazard ratios (HRs) and the 95\% confidence intervals (CIs) for the relationship between habitual meat consumption and incident impairment in physical functioning. The study sample was categorized into tertiles of meat intake, using the first (lowest intake) as the reference category. Additionally, the analyses were repeated for a (continuous) increase of $100 \mathrm{~g} /$ day in meat intake to assess a linear dose-response relation. We conducted analyses for each different type of meat and for the different domains of physical functioning (agility, mobility, and lower-extremity function).

The duration of follow-up was determined by the period from the date of study entry to the date of assessment of physical limitation, loss to follow-up, death, or the end of the study, whichever came first. Three Cox models were built: the first adjusting for age and sex; a second model with additional adjustment for educational level, smoking status, alcohol intake, energy intake, BMI, sedentary behavior, and morbidity (cognitive decline, osteomuscular disease, cardiovascular disease, cancer, chronic lung disease and depression requiring treatment), to understand their impact on the studied association; and a third model, additionally adjusted for the following food groups: vegetables, legumes, fruit, nuts, cereals, dairy, and fish (all in quintiles of g/day). The variables in the model that had been measured at baseline and in 2012 were updated in the follow-up.

We conducted several sensitivity analyses. A possible modifying effect of sex was tested by using likelihoodratio tests, which compared models with and without cross-product interaction terms. Given that we found no sex interactions, our results are presented for the total sample. Also, those associations that were found to be significant were stratified by sex, age, and obesity to assess the robustness of the results. Furthermore, because of possible synergistic effects of physical activity and protein intake [22], we additionally stratified by physical activity (above and below the median) and total protein intake (above and below the median). Lastly, we estimated the effect of replacing a serving per day of processed meat by red meat, poultry, or an alternative protein source, by including both forms of consumption as continuous variables in the model. The differences in the beta coefficients were used to estimate the HR and 95\% CI of the substitution associations.

The proportionality assumption was checked visually by $\log$ minus $\log$ plots with no deviations detected. Differences in population characteristics between categories of consumption were assessed by ANOVA followed by Tukey tests for continuous variables, and by the chisquare test for categorical variables. Statistical significance was set at two-tailed $p<0.05$. Analyses were conducted using SAS software, version 9.4 (SAS Institute Inc.).

\section{Results}

In this population, mean (standard deviation) consumption was 35.0 (34.0) g/day for processed meat, 


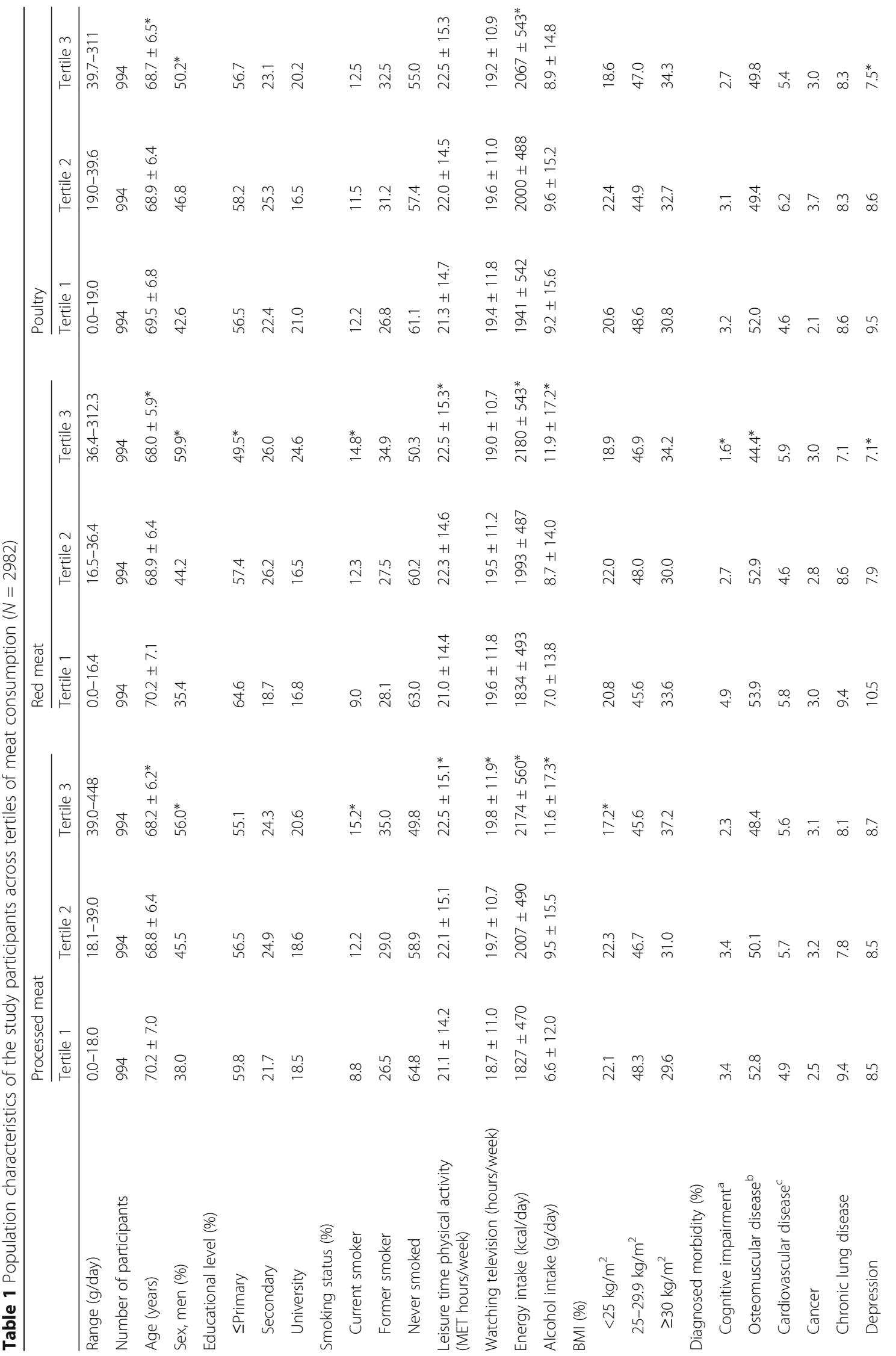




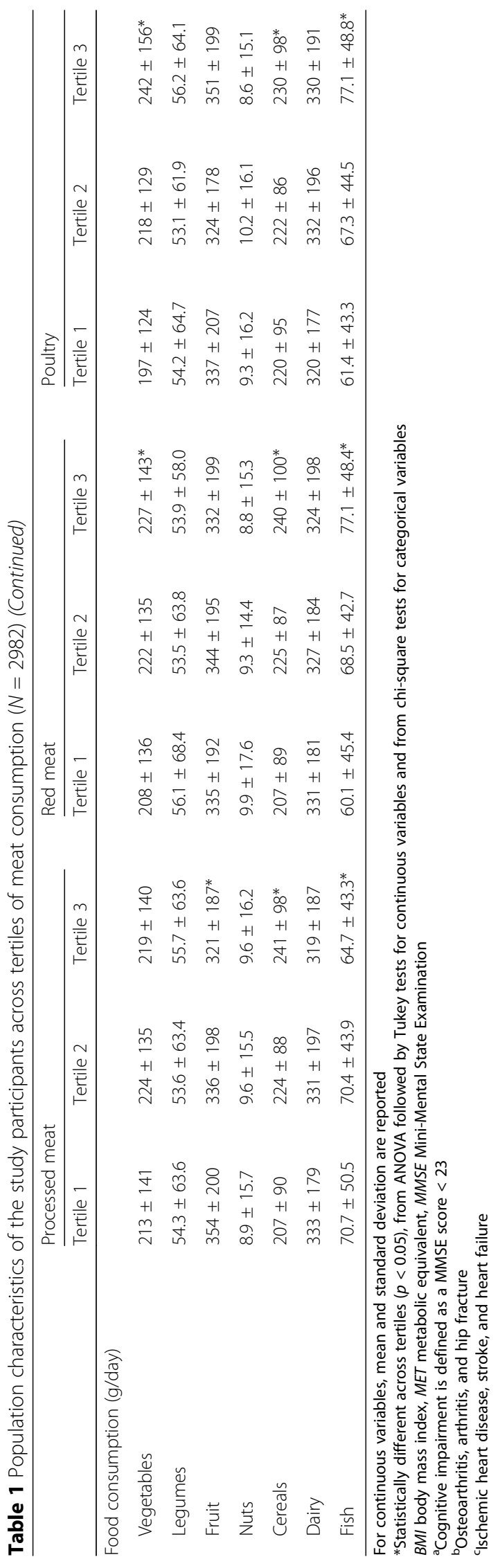


31.9 (28.2) g/day for red meat, and 33.8 (28.3) g/day for poultry. The correlations between the intake of the different meat categories (in g/day) were: $r=0.05, p=0.01$ (between processed meat and red meat), $r=-0.02$, $p=0.21$ (between processed meat and poultry), and $r=0.11, p<0.01$ (between red meat and poultry). Participants in the highest tertile of processed meat consumption were significantly younger, were more often men, were more often current smokers, were more physically active, spent more time watching television, had higher energy and alcohol intake, and ate less fruit and fish compared to those in the lowest tertile of consumption. In addition, those in the highest tertile of red meat consumption were more educated and less likely to have cognitive impairment, osteomuscular disease, or depression, and had a higher vegetable consumption than those in the lowest tertile (Table 1).

During a median of 5.2 years of follow-up, we identified 625 participants with incident impaired agility, 455 with impaired mobility, and 446 with impaired lowerextremity function. Those in the highest tertile of processed meat consumption showed a higher risk of impaired agility (model 3, HR for highest vs. lowest tertile: 1.33 95\% CI: 1.08-1.64; $p$ trend = 0.01). A 100 g/ day increase in processed meat consumption was associated with a $23 \%$ higher risk of impaired agility (HR 1.23; 95\% CI: 1.00-1.53) (Table 2). Red meat and poultry consumption were not associated with agility limitation.

Higher consumption of processed meat was also associated with impaired lower-extremity function (model 3, HR for highest vs. lowest tertile: 1.31; 95\% CI: 1.02-1.68; $p$ trend $=0.04)$ (Table 3). Again, neither red meat nor poultry were associated with physical function, as assessed with the SPPB. In addition, none of the meat types was associated with limitations in mobility (Additional file 1: Table S1).

Figure 1 shows the associations of processed meat consumption with impaired agility and lower-extremity function stratified by socio-demographic variables and health behaviors. We found no significant differences between the strata ( $p$ for interaction $>0.05$ ). Lastly, in the substitution analyses, replacing one serving per day of processed meat by one serving per day of red meat, poultry, or other important protein sources (fish, legumes, dairy, and nuts) was associated with a lower risk of agility. The results were in the same direction for

Table $2 \mathrm{HR}$ and 95\% Cl for the association between meat consumption and impairment in agility

\begin{tabular}{|c|c|c|c|c|c|}
\hline & \multicolumn{3}{|c|}{ Meat intake } & \multirow[b]{2}{*}{$P$ trend } & \multirow{2}{*}{$\begin{array}{l}\text { Continuous } \\
\text { per } 100 \mathrm{~g} / \text { day }\end{array}$} \\
\hline & Tertile 1 & Tertile 2 & Tertile 3 & & \\
\hline N participants & 893 & 894 & 894 & & 2681 \\
\hline \multicolumn{6}{|l|}{ Processed meat } \\
\hline Mean intake (g/day) & $8.5 \pm 27.9$ & $27.9 \pm 6.1$ & $69.6 \pm 38.0$ & & $35.3 \pm 34.0$ \\
\hline Impairment in agility ( $n /$ person-years) & $188 / 4220$ & $214 / 4469$ & $223 / 4360$ & & $625 / 13,049$ \\
\hline Model 1 & Reference & $1.09(0.90-1.33)$ & $1.38(1.13-1.68)$ & 0.001 & $1.35(1.11-1.64)$ \\
\hline Model 2 & Reference & $1.08(0.89-1.32)$ & $1.31(1.07-1.60)$ & 0.01 & $1.30(1.05-1.62)$ \\
\hline Model 3 & Reference & $1.14(0.93-1.39)$ & $1.33(1.08-1.64)$ & 0.01 & $1.23(1.00-1.53)$ \\
\hline \multicolumn{6}{|l|}{ Red meat } \\
\hline Mean intake (g/day) & $7.5 \pm 5.4$ & $26.4 \pm 5.9$ & $63.7 \pm 27.0$ & & $32.5 \pm 28.5$ \\
\hline Impairment in agility ( $n /$ person-years) & $230 / 4313$ & $220 / 4391$ & $175 / 4345$ & & $625 / 13,049$ \\
\hline Model 1 & Reference & $1.04(0.87-1.26)$ & $1.03(0.84-1.26)$ & 0.77 & $1.02(0.95-1.08)$ \\
\hline Model 2 & Reference & $1.13(0.93-1.36)$ & $1.13(0.92-1.40)$ & 0.22 & $1.23(0.88-1.70)$ \\
\hline Model 3 & Reference & $1.15(0.95-1.40)$ & $1.14(0.92-1.41)$ & 0.20 & $1.07(0.96-1.19)$ \\
\hline \multicolumn{6}{|l|}{ Poultry } \\
\hline Mean intake (g/day) & $9.1 \pm 6.6$ & $28.7 \pm 5.5$ & $64.2 \pm 28.6$ & & $34.0 \pm 28.6$ \\
\hline Impairment in agility ( $n /$ person-years) & $200 / 4278$ & $227 / 4435$ & $198 / 4336$ & & $625 / 13,049$ \\
\hline Model 1 & Reference & $1.15(0.95-1.39)$ & $1.04(0.86-1.27)$ & 0.66 & $0.93(0.69-1.25)$ \\
\hline Model 2 & Reference & $1.10(0.91-1.33)$ & $1.02(0.84-1.25)$ & 0.83 & $0.90(0.66-1.23)$ \\
\hline Model 3 & Reference & $1.14(0.94-1.38)$ & $1.07(0.88-1.32)$ & 0.48 & $0.94(0.69-1.29)$ \\
\hline
\end{tabular}

Model 1 is adjusted for age and sex

Model 2 is adjusted for age, sex, educational level (<primary, secondary, or university), smoking status (never smoked, former smoker, or current smoker), alcohol intake (quintiles of g/day), energy intake (quintiles of kcal/day), BMI $\left(<25,25<30, \geq 30 \mathrm{~kg} / \mathrm{m}^{2}\right.$ ), sedentary behavior (quintiles of hours/week watching television), and morbidity (cognitive impairment, osteomuscular disease, cardiovascular disease, cancer, chronic lung disease, or depression) Model 3 is, additionally, adjusted for vegetables, legumes, fruits, nuts, cereals, dairy, and fish consumption (quintiles of g/day) $B M I$ body mass index, $\mathrm{Cl}$ confidence interval, $H R$ hazard ratio 
Table $3 \mathrm{HR}$ and 95\% Cl for the association between meat consumption and impaired lower-extremity function

\begin{tabular}{|c|c|c|c|c|c|}
\hline & \multicolumn{3}{|c|}{ Meat intake } & \multirow[b]{2}{*}{$P$ trend } & \multirow{2}{*}{$\begin{array}{l}\text { Continuous } \\
\text { per } 100 \mathrm{~g} / \text { day }\end{array}$} \\
\hline & Tertile 1 & Tertile 2 & Tertile 3 & & \\
\hline$N$ participants & 994 & 994 & 994 & & 2982 \\
\hline \multicolumn{6}{|l|}{ Processed meat } \\
\hline Mean intake (g/day) & $8.2 \pm 5.8$ & $27.6 \pm 6.1$ & $69.3 \pm 38.1$ & & $35.0 \pm 34.0$ \\
\hline Impairment of lower-extremity function, n/person-years & $131 / 4450$ & $153 / 4778$ & $162 / 4685$ & & $446 / 13,914$ \\
\hline Model 1 & Reference & $1.14(0.90-1.44)$ & $1.50(1.18-1.89)$ & 0.001 & $1.27(0.97-1.67)$ \\
\hline Model 2 & Reference & $1.15(0.91-1.46)$ & $1.37(1.07-1.75)$ & 0.01 & $1.12(0.83-1.52)$ \\
\hline Model 3 & Reference & $1.22(0.96-1.56)$ & $1.31(1.02-1.68)$ & 0.04 & $1.00(0.72-1.38)$ \\
\hline \multicolumn{6}{|l|}{ Red meat } \\
\hline Mean intake (g/day) & $7.1 \pm 5.3$ & $25.7 \pm 5.9$ & $62.8 \pm 26.8$ & & $31.9 \pm 28.2$ \\
\hline Impairment of lower-extremity function ( $n /$ person-years) & $166 / 4504$ & $169 / 4737$ & $111 / 4672$ & & $446 / 13,914$ \\
\hline Model 1 & Reference & $1.13(0.91-1.40)$ & $0.89(0.69-1.14)$ & 0.43 & $0.75(0.49-1.14)$ \\
\hline Model 2 & Reference & $1.19(0.96-1.49)$ & $0.87(0.68-1.13)$ & 0.42 & $0.69(0.45-1.06)$ \\
\hline Model 3 & Reference & $1.25(1.00-1.56)$ & $0.86(0.67-1.12)$ & 0.43 & $0.70(0.45-1.06)$ \\
\hline \multicolumn{6}{|l|}{ Poultry } \\
\hline Mean intake (g/day) & $9.0 \pm 6.6$ & $28.6 \pm 5.6$ & $64.0 \pm 27.8$ & & $33.8 \pm 28.3$ \\
\hline Impairment of lower-extremity function, n/person-years & $139 / 4542$ & $171 / 4590$ & $136 / 4590$ & & $446 / 13,914$ \\
\hline Model 1 & Reference & $1.27(1.02-1.60)$ & $1.03(0.81-1.30)$ & 0.81 & $1.24(0.86-1.80)$ \\
\hline Model 2 & Reference & $1.30(1.03-1.63)$ & $1.00(0.79-1.28)$ & 0.99 & $1.15(0.79-1.68)$ \\
\hline Model 3 & Reference & $1.34(1.06-1.69)$ & $1.08(0.85-1.38)$ & 0.50 & $1.31(0.90-1.91)$ \\
\hline
\end{tabular}

Model 1 is adjusted for age and sex

Model 2 is adjusted for age, sex, educational level ( $\leq$ primary, secondary, or university), smoking status (never smoked, former smoker, or current smoker), alcohol intake (quintiles of $\mathrm{g} /$ day), energy intake (quintiles of $\mathrm{kcal} /$ day), BMI $\left(<25,25<30, \geq 30 \mathrm{~kg} / \mathrm{m}^{2}\right.$ ), sedentary behavior (quintiles of hours/week watching television), and morbidity (cognitive impairment, osteomuscular disease, cardiovascular disease, cancer, chronic lung disease, and depression)

Model 3 is, additionally, adjusted for vegetables, legumes, fruits, nuts, cereals, dairy, and fish consumption (quintiles of g/day)

$B M I$ body mass index, $\mathrm{Cl}$ confidence interval, $H R$ hazard ratio

impaired lower-extremity function, although they did not achieve statistical significance in all cases (Table 4).

\section{Discussion}

In this study, a higher habitual consumption of processed meat was associated with increased risk of impaired agility and lower-extremity function. In addition, substitution of processed meat with fish, legumes, dairy, or nuts was associated with reduced risk of functional impairment. We tried to capture the broad dimension of physical functioning using several self-reported and performance-based measurements, since self-reported measures assess the perception of the ability to perform a functional task and performance-based measures assess the ability to complete a task.

No significant associations between red meat or poultry and physical function were found. Since red meat has been strongly associated with increased mortality [17], it is possible that the low consumption in this cohort was not enough to reveal a detrimental impact on physical functioning. Similarly, it is possible that the intake of poultry was not high enough to show a plausible beneficial effect; however, substitution analyses showed that replacement of processed meat for poultry reduced the risk of impaired function.

Few studies have investigated the association between meat intake and physical functioning. A recent paper among participants of the Framingham Offspring study investigated the association of the consumption of several protein sources with skeletal muscle mass and functional decline [22]. A higher intake of red meat and poultry was associated with higher muscle mass, especially among women. However, in line with our results, consumption of red meat and poultry was not significantly associated with developing two or more functional impairments; only when this consumption was combined with high physical activity were there beneficial effects on functional status [22]. In addition, in a randomized trial, participants receiving a proteinenriched diet through the addition of $160 \mathrm{~g} /$ day of lean red meat combined with resistance training showed a greater increase in leg-extension muscle strength after 4 months, compared with the control group that only underwent resistance training [32]. However, muscle function, measured through a four-square step test, a times-up-and-go test, and a 30-s sit-to-stand test, did 
Impairment in agility

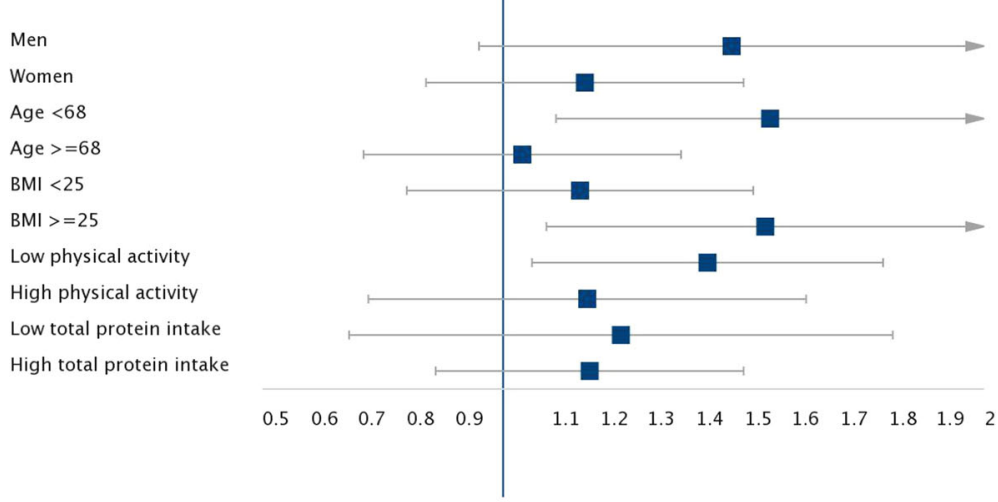

Impairment in lower extremity function
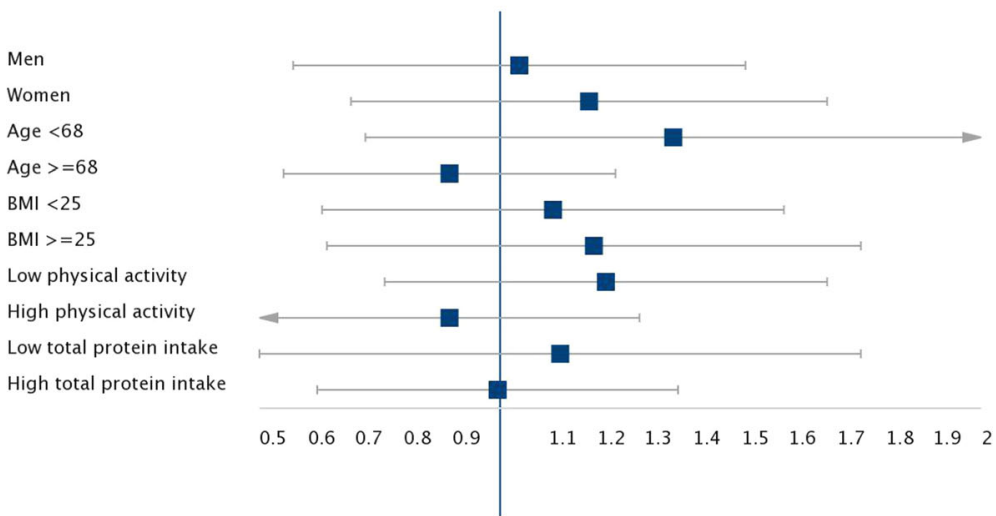

Fig. 1 Stratified analyses for the associations between processed meat consumption and impaired physical function during a median follow-up of 5.2 years. Models were adjusted for age, sex, educational level (sprimary, secondary, or university), smoking status (never smoked, former smoker, or current smoker), alcohol intake (quintiles of $\mathrm{g} /$ day), energy intake (quintiles of $\mathrm{kcal} /$ day), BMl $\left(<25,25<30, \geq 30 \mathrm{~kg} / \mathrm{m}^{2}\right.$ ), sedentary behavior (quintiles of hours/week watching television), morbidity (cognitive impairment, osteomuscular disease, cardiovascular disease, cancer, chronic lung disease, or depression), and for vegetables, legumes, fruits, nuts, cereals, dairy, and fish consumption (quintiles of g/day). BMl body mass index

Table $4 \mathrm{HR}$ and 95\% Cl for replacing one serving per day of processed meat for another source of protein

\begin{tabular}{lll}
\hline Substitution & $\begin{array}{l}\text { Impairment } \\
\text { in agility }\end{array}$ & $\begin{array}{l}\text { Impairment in } \\
\text { lower-extremity function }\end{array}$ \\
\hline $\begin{array}{l}\text { Red meat for } \\
\text { processed meat }\end{array}$ & $0.96(0.86-1.07)$ & $0.63(0.56-0.72)$ \\
Poultry for processed meat & $0.70(0.64-0.77)$ & $1.03(0.95-1.10)$ \\
Fish for processed meat & $0.82(0.75-0.90)$ & $0.68(0.63-0.73)$ \\
Legumes for processed meat & $0.86(0.76-0.99)$ & $0.97(0.79-1.20)$ \\
Dairy for processed meat & $0.75(0.65-0.88)$ & $0.85(0.68-1.06)$ \\
Nuts for processed meat & $0.59(0.57-0.61)$ & $0.60(0.55-0.65)$ \\
\hline
\end{tabular}

Model is adjusted for age, sex, educational level ( $\leq$ primary, secondary, or university), smoking status (never smoked, former smoker, or current smoker), alcohol intake (quintiles of $\mathrm{g} /$ day), energy intake (quintiles of $\mathrm{kcal} /$ day), BMI $\left(<25,25<30, \geq 30 \mathrm{~kg} / \mathrm{m}^{2}\right)$, sedentary behavior (quintiles of hours/week watching television), and morbidity (cognitive impairment, osteomuscular disease, cardiovascular disease, cancer, chronic lung disease, or depression) One serving of red meat, processed meat, poultry, and fish $=100 \mathrm{~g}$; one serving of legumes $=75 \mathrm{~g}$; one serving of dairy $=150 \mathrm{~g}$; one serving of nuts $=30 \mathrm{~g}$ $B M I$ body mass index, $\mathrm{Cl}$ confidence interval, $H R$ hazard ratio not differ between the two randomized groups. We stratified our analyses by physical activity to compare our results with these findings, but we did not observe any joint association between meat intake and high physical activity level on subsequent physical function. In addition, the investigators of the Framingham Third Generation Study identified clusters of people who consumed a high amount of red meat and chicken; these clusters did not show an association with muscle mass or muscle strength [33].

There are several potential mechanisms for the association of processed meat and functional impairment. Protein is an important component of meat; however, meat and especially processed meat also contain a considerable amount of saturated and trans fat. These types of fat have previously been shown to increase inflammation [34], which may subsequently reduce physical functioning [35]. Additionally, compared to red meat and poultry, the content of sodium and nitrites is much 
higher in processed meat [36, 37]. Sodium and nitrites may increase cardiovascular disease risk through increased blood pressure and endothelial dysfunction [38, 39]. This suggests that the beneficial effect of the high-quality protein in meat might be counterbalanced by the high content of saturated and trans fat, sodium, and nitrite in processed meat. This hypothesis is supported because the risk of physical function impairment lowered when processed meat was replaced by other protein sources.

Fish is a common substitute for meat. Processed meat was inversely correlated with fish consumption. Since in our cohort fish consumption was relatively high $(67.3 \mathrm{~g} /$ day $)$ and this food is an important source of omega- 3 fatty acids with anti-inflammatory effects [34], it is plausible that some of the detrimental effect of processed meat was due to the lack of consumption of fish. However, when we adjusted the analyses for this and other food groups, the associations still held.

The strengths of this study are its prospective design, the estimation of habitual meat intake through a validated diet history, and the repeated measurements during follow-up, which allowed us to calculate the cumulative average consumption and to update confounding factors over time, which reduces the number of random errors and improves the precision of estimates. However, certain misreporting and misclassification of dietary intake cannot be ruled out, even though we excluded participants with an implausibly high or low energy intake level. Some further limitations should also be acknowledged. The self-reported physical function measures may be less reliable than objective measurements. However, reported function has been shown to predict early decline in performance and early disease [40]. Finally, as in any observational study, some residual confounding may persist.

\section{Conclusions}

A higher consumption of processed meat, but not red meat or poultry, was associated with increased risk of impaired agility and lower-extremity function in older adults. We did not find evidence that meat, despite its high content of protein, has a protective effect on impairment in physical functioning. These results should be confirmed in future research in countries with a higher meat intake.

\section{Additional file}

Additional file 1: Table S1. HR and 95\% Cl for the association between meat consumption and impairment in mobility. (PDF $173 \mathrm{~kb}$ )

\section{Abbreviations}

BMl: Body mass index; $\mathrm{Cl}$ : Confidence interval: HR: Hazard ratio: MMSE: Mini-Mental State Examination; SPPB: Short Physical Performance Battery

\section{Acknowledgements}

Not applicable.

\section{Funding}

This work was supported by grants from the Instituto de Salud Carlos III, State Secretary of R+D+l of Spain and FEDER/FSE (FIS 13/0288, 16/609 and 16/1512), and the European Union: FP7-HEALTH-2012-Proposal No: 305483-2, "Utility of omic-based biomarkers in characterizing older individuals at risk for frailty, its progression to disability and general consequences to health and wellbeing - The FRAILOMIC Initiative"; EU H2020- Project ID: 635316, " Ageing Trajectories of Health: Longitudinal Opportunities and Synergies- The ATHLOS project"; and the JPI HDHL: "Salivary Markers of Diet and Health- The SALAMANDER project".

\section{Availability of data and materials}

The data set analyzed during the current study is not publicly available since the consent obtained from participants did not include permission for their data to be shared publicly. However, the data are available from the principal investigator (FRA) on reasonable request.

\section{Authors' contributions}

$E A S, J R B, F R A$, and ELG designed the research and revised the manuscript for important intellectual content. EAS analyzed the data. EAS and ELG wrote the manuscript. ELG had primary responsibility for the final content. All authors read and approved the final manuscript.

Ethics approval and consent to participate

Ethical approval was obtained from the Clinical Research Ethics Committee of La Paz University Hospital in Madrid (reference PI-1793). Study participants gave written informed consent. Registration: ClinicalTrials.gov NCT01133093.

Consent for publication

Not applicable.

\section{Competing interests}

The authors declare that they have no competing interests.

\section{Publisher's Note}

Springer Nature remains neutral with regard to jurisdictional claims in published maps and institutional affiliations.

\section{Author details}

${ }^{1}$ Department of Preventive Medicine and Public Health, School of Medicine, Universidad Autónoma de Madrid, Avda. Arzobispo Morcillo, 4, 28029 Madrid, Spain. ${ }^{2}$ CIBERESP (CIBER of Epidemiology and Public Health), Madrid, Spain. ${ }^{3}$ IMDEA Food Institute, CEI UAM+CSIC, Madrid, Spain.

Received: 8 November 2017 Accepted: 13 March 2018

Published online: 05 April 2018

\section{References}

1. United Nations, Department of Economic and Social Affairs, Population Division. World Population Prospects: The 2017 Revision, Key Findings and Advance Tables. Working Paper No. ESA/P/WP.248, 2017.

2. Prince MJ, Wu F, Guo Y, Robledo LMG, O'Donnell M, Sullivan R, et al. The burden of disease in older people and implications for health policy and practice. Lancet. 2015;385(9967):549-62.

3. Stefanick ML, Brunner RL, Leng X, Limacher MC, Bird CE, Garcia DO, et al. The relationship of cardiovascular disease to physical functioning in women surviving to age 80 and above in the Women's Health Initiative. J Gerontol A Biol Sci Med Sci. 2016;71(Suppl 1):S42-53.

4. Cesari M, Penninx BW, Pahor M, Lauretani F, Corsi AM, Williams GR, et al. Inflammatory markers and physical performance in older persons: the InCHIANTI study. J Gerontol A Biol Sci Med Sci. 2004;59(3):M242-8.

5. Semba RD, Ferrucci L, Sun K, Walston J, Varadhan R, Guralnik JM, et al. Oxidative stress and severe walking disability among older women. Am J Med. 2007:120(12):1084-9.

6. Guallar-Castillón P, Sagardui-Villamor J, Banegas JR, Graciani A, Fornés NS, López García E, et al. Waist circumference as a predictor of disability among older adults. Obesity. 2007;15(1):233-44.

7. Artaud F, Dugravot A, Sabia S, et al. Unhealthy behaviours and disability in older adults: Three-City Dijon cohort study. BMJ. 2013;347:f4240. 
8. Mann J, Truswell AS, editors. Essentials of human nutrition. 4th ed. New York: Oxford University Press; 2012.

9. Farsijani S, Payette H, Morais JA, Shatenstein B, Gaudreau P, Chevalier S. Even mealtime distribution of protein intake is associated with greater muscle strength, but not with 3-y physical function decline, in free-living older adults: the Quebec longitudinal study on Nutrition as a Determinant of Successful Aging (NuAge study). Am J Clin Nutr. 2017;106(1):113-24.

10. Beasley JM, Wertheim BC, LaCroix AZ, Prentice RL, Neuhouser ML, Tinker LF, et al. Biomarker-calibrated protein intake and physical function in the women's health initiative. J Am Geriatr Soc. 2013;61(11):1863-71.

11. Isanejad M, Mursu J, Sirola J, Kröger H, Rikkonen T, Tuppurainen M, et al. Dietary protein intake is associated with better physical function and muscle strength among elderly women. Br J Nutr. 2016;115(7):1281-91.

12. Sahni S, Mangano KM, Hannan MT, Kiel DP, McLean RR. Higher protein intake is associated with higher lean mass and quadriceps muscle strength in adult men and women. J Nutr. 2015;145(7):1569-75.

13. McLean RR, Mangano KM, Hannan MT, Kiel DP, Sahni S. Dietary protein intake is protective against loss of grip strength among older adults in the Framingham Offspring Cohort. J Gerontol A Biol Sci Med Sci. 2015;71(3):356-61.

14. Sandoval-Insausti H, Pérez-Tasigchana RF, López-García E, García-Esquinas E, Rodríguez-Artalejo F, Guallar-Castillón P. Macronutrients intake and incident frailty in older adults: a prospective cohort study. J Gerontol A Biol Sci Med Sci. 2016;71(10):1329-34.

15. Struijk EA, Lana A, Guallar-Castillon P, Rodríguez-Artalejo F, Lopez-Garcia E. Intake of B vitamins and impairment in physical function in older adults. Clin Nutr. 2017; https://doi.org/10.1016/j.clnu.2017.05.016.

16. Sacks FM, Lichtenstein AH, JHY W, Appel LJ, Creager MA, Kris-Etherton PM, et al. Dietary fats and cardiovascular disease: a presidential advisor from the American Heart Association. Circulation. 2017;136:e1-23.

17. Wang X, Lin X, Ouyang YY, Liu J, Zhao G, Pan A, et al. Red and processed meat consumption and mortality: dose-response meta-analysis of prospective cohort studies. Public Health Nutr. 2016;19(5):893-905.

18. Bibas L, Levi M, Bendayan M, Mullie L, Forman DE, Afilalo J. Therapeutic interventions for frail elderly patients: part I. Published randomized trials. Prog Cardiovasc Dis. 2014;57:134-43.

19. Bouillon K, Batty GD, Hamer M, Sabia S, Shipley MJ, Britton A, et al. Cardiovascular disease risk scores in identifying future frailty: the Whitehall II prospective cohort study. Heart. 2013;99:737-42.

20. Gale CR, Cooper C, Sayer AA. Framingham cardiovascular disease risk scores and incident frailty: the English longitudinal study of ageing. Age. 2014; 36(4):9692.

21. Robinson SM, Reginster JY, Rizzoli R, Shaw SC, Kanis JA, Bautmans I, et al. Does nutrition play a role in the prevention and management of sarcopenia? Clin Nutr. 2017; https://doi.org/10.1016/j.clnu.2017.08.016.

22. Bradlee ML, Mustafa J, Singer MR, Moore LL. High-protein foods and physical activity protect against age-related muscle loss and functional decline. J Gerontol A Biol Sci Med Sci. 2017; https://doi.org/10.1093/gerona/glX070.

23. Rodríguez-Artalejo F, Graciani A, Guallar-Castillón P, León-Muñoz LM, Zuluaga MC, López-García E, et al. Rationale and methods of the study on nutrition and cardiovascular risk in Spain (ENRICA). Rev Esp Cardiol. 2011; 64(10):876-82

24. León-Muñoz LM, García-Esquinas E, López-García E, Banegas JR, RodríguezArtalejo F. Major dietary patterns and risk of frailty in older adults: a prospective cohort study. BMC Med. 2015;13(1):11.

25. Morley JE, Malmstrom TK, Miller DK. A simple frailty questionnaire (FRAIL) predicts outcomes in middle aged African Americans. J Nutr Health Aging. 2012;16:601-8

26. Guallar-Castillón P, Sagardui-Villamor J, Balboa-Castillo T, Sala-Vila A, Ariza Astolfi MJ, Sarrión Pelous MD, et al. Validity and reproducibility of a Spanish dietary history. PLoS One. 2014;9(1):e86074.

27. Rosow I, Breslau N. A Guttman health scale for the aged. J Gerontol. 1966; 21:556-9.

28. Guralnik JM, Ferrucci L, Pieper CF, Leveille SG, Markides KS, Ostir GV, et al. Lower-extremity function and subsequent disability: consistency across studies, predictive models, and value of gait speed alone compared with the Short Physical Performance Battery. J Gerontol A Biol Sci Med Sci. 2000; 55:M221-31

29. Pols MA, Peeters PH, Ocke MC, Slimani N, Bueno-de-Mesquita HB, Collette $\mathrm{HJ}$. Estimation of reproducibility and relative validity of the questions included in the EPIC Physical Activity Questionnaire. Int J Epidemiol. 1997;26(suppl 1):S181.
30. Graciani A, Banegas JR, Guallar-Castillón P, Domínguez-Rojas V, RodríguezArtalejo F. Cognitive assessment of the non-demented elderly community dwellers in Spain. Dement Geriatr Cogn Disord. 2006;21(2):104-12.

31. Martínez-Gómez D, Guallar-Castillón P, León-Muñoz LM, López-García E, Rodríguez-Artalejo F. Combined impact of traditional and non-traditional health behaviors on mortality: a national prospective cohort study in Spanish older adults. BMC Med. 2013;11:47.

32. Daly RM, O'Connell SL, Mundell NL, Grimes CA, Dunstan DW, Nowson CA. Protein-enriched diet, with the use of lean red meat, combined with progressive resistance training enhances lean tissue mass and muscle strength and reduces circulating IL-6 concentrations in elderly women: a cluster randomized controlled trial. Am J Clin Nutr. 2014;99(4):899-910.

33. Mangano KM, Sahni S, Kiel DP, Tucker KL, Dufour AB, Hannan MT. Dietary protein is associated with musculoskeletal health independently of dietary pattern: the Framingham Third Generation Study. Am J Clin Nutr. 2017; https://doi.org/10.3945/ajen.116.136762.

34. Giugliano D, Ceriello A, Esposito K. The effects of diet on inflammation. J Am Coll Cardiol. 2006;48(4):677-85.

35. Brinkley TE, Leng X, Miller ME, Kitzman DW, Pahor M, Berry MJ, et al. Chronic inflammation is associated with low physical function in older adults across multiple comorbidities. J Gerontol A Biol Sci Med Sci. 2009;64(4):455-61.

36. Micha R, Wallace SK, Mozaffarian D. Red and processed meat consumption and risk of incident coronary heart disease, stroke, and diabetes mellitus: a systematic review and meta-analysis. Circulation. 2010;121:2271-83.

37. Banegas JR, Rodríguez-Artalejo F. The Strong Heart Study: adding biological plausibility to the red meat-cardiovascular disease association. J Hypertens. 2017;35(9):1782-4.

38. Micha R, Michas G, Mozaffarian D. Unprocessed red and processed meats and risk of coronary artery disease and type 2 diabetes-an updated review of the evidence. Curr Atheroscler Rep. 2012;14:515-24.

39. Kleinbongard P, Dejam A, Lauer T, Jax T, Kerber S, Gharini P, et al. Plasma nitrite concentrations reflect the degree of endothelial dysfunction in humans. Free Radic Biol Med. 2006:40(2):295-302.

40. Fried LP, Young $Y$, Rubin G. Self-reported preclinical disability identifies older women with early declines in performance and early disease. J Clin Epidemiol. 2001;54(9):889-901.

\section{Submit your next manuscript to BioMed Central and we will help you at every step:}

- We accept pre-submission inquiries

- Our selector tool helps you to find the most relevant journal

- We provide round the clock customer support

- Convenient online submission

- Thorough peer review

- Inclusion in PubMed and all major indexing services

- Maximum visibility for your research

Submit your manuscript at www.biomedcentral.com/submit
Biomed Central 